\title{
Study on Energy Dissipation Characteristics and Damage Law of Backfill under Cyclic Impact
}

\author{
Xianglong Li $\mathbb{D}^{1,2}$ Qinglian Zhou $\mathbb{D D}^{1}{ }^{1}$ Jianguo Wang $\mathbb{D}^{1,2}$ Wei Sun ${ }^{10},{ }^{1,2}$ Yongxin Yao, ${ }^{1}$ \\ Yongbo $W u,{ }^{1}$ and Zhiping Zhang ${ }^{1}$ \\ ${ }^{1}$ Faculty of Land Resources Engineering, Kunming University of Science and Technology, Kunming, Yunnan, China \\ ${ }^{2}$ Yunnan Key Laboratory of China-German Blue Mining and Utilization of Special Underground Space, Kunming, China \\ Correspondence should be addressed to Jianguo Wang; wangjg0831@163.com and Wei Sun; kmustsw@qq.com
}

Received 5 November 2021; Revised 5 January 2022; Accepted 26 January 2022; Published 21 February 2022

Academic Editor: Bin Gong

Copyright ( $\odot 2022$ Xianglong Li et al. This is an open access article distributed under the Creative Commons Attribution License, which permits unrestricted use, distribution, and reproduction in any medium, provided the original work is properly cited.

\begin{abstract}
This research aims to study the damaging effect of underground blasting mining pillars on adjacent cemented filling bodies. The filling bodies were made by mixing ore rock with ash sand by the ratio of $1: 4$ and $1: 6$, respectively, which were subjected to cyclic impact tests with the split-Hopkinson pressure bar under the pressure of $0.2 \mathrm{MPa}$ and $0.24 \mathrm{MPa}$ to analyze the energy dissipation characteristics and damage law. The results showed that as the stress wave induced by the cyclic impact was transmitted to the composite specimen, the energy was absorbed for crack growth and development. Then, the energy reflection ratio increased while the energy dissipation ratio and transmission ratio decreased. For the combined specimen with the cement-sand ratio of $1: 4$, after five cycles of impact under the condition of $I p=0.2 \mathrm{MPa}$, the damage variables were $0.07,0.11,0.51$, and 0.56 , respectively, since the second time; under the condition of $I p=0.24 \mathrm{MPa}$, the damage variables were $0.17,0.29,0.55$, and 0.66 , respectively. After reaching the damage threshold of 0.63 , the damage variable showed nonlinearity. Moreover, it was found that the mechanical properties of the filling body affect the whole combined specimen, and the dynamic strength of the combined specimen with the cement-sand ratio of $1: 4$ was higher than that of the cement-sand ratio of $1: 6$. Therefore, it can be concluded that during the twostep pillar recovery, the amount of blasting explosive can be appropriately reduced, and the number of blasting can be increased to reduce the damaging effect of blasting impact on the cemented pillar and reserved pillar to maintain stability.
\end{abstract}

\section{Introduction}

Subsequent filling mining method [1] is widely used in underground mining; in the second step of pillar mining, the explosion stress wave induced by blasting will enter the adjacent cemented filling body from ore rock, which usually causes damage to ore rock and filling body. The disturbance of blasting impact load to ore rock pillar and the artificial pillar can make the original microcracks inside the pillar expand and be connected to form a macrofault surface. Besides, the impact load has a significant influence on the deformation process and mechanical properties of the pillar. The failure of the ore rock and filling body involves a complex dynamic mechanical process [2-5], which seriously affects safety during mining.
Many studies have been conducted on the dynamic characteristics of rock, ore, or backfill [6-13]. Xie et al. [14] believed that energy dissipation would lead to lithology deterioration and strength reduction during the rock deformation and failure process. Zhu et al. [15] found a positive correlation between compressive strength and backfill with different proportions. Hou et al. [16] found the relationship between compressive strength and reinforcement factor of cemented backfill under different strain rates and concluded the variation law of compressive strength and dissipated energy density. Hu et al. [7]studied the cumulative damage effect of rock mass under blasting and revealed goaf's failure and instability mechanism. Zhu et al. [17] conducted an impact test on sandstone and analyzed the failure process of rock from the perspective of mesoscopic crack propagation and energy absorption. Literature [18-23] 
explored the damage evolution law of different rock masses under the cyclic impact and believed that cyclic impact and prestatic loading had nonlinear effects on the whole rock damage. Yang et al. [24] simulated blasting experiments for marble under different blasting conditions and analyzed the damage characteristics. Jin et al. [25] established a rock damage evolution model and explored the influence of static load on rock damage. Based on the deformation and failure characteristics of rock, Xiao et al. [26] proposed an inverted S-type damage evolution model and studied the influence of the initial damage degree on the mechanical fatigue properties of rock, such as stress amplitude and loading waveform changes and frequency. Through the uniaxial compression test, Zhao et al. [27] studied the mechanical properties and cooperative deformation characteristics of cemented tailings filling materials with different cementsand ratios. Cao et al. [28]studied the variation rule and failure mode of mechanical characteristics of cemented filling with layered tailings. Liu et al. [29] proposed a new method of studying the rock deformation, failure, and instability of surrounding under load.

In terms of the dynamic characteristics of composite specimens, Yang et al. [30] conducted impact tests on composite rock samples with large wave impedance splicing of red sandstone and grey stone and summarized the stressstrain relationship and capacity dissipation law. Wang [31] carried out a quasi-triaxial loading test and analyzed the deformation evolution law of underground surrounding rock-filling body composition. Wang et al. [32] analyzed the rupture evolution law of cemented tailings cemented backfill. However, there is rarely any study about the adjacent structure of pillar and filling body and its response characteristics under the disturbance of blasting dynamic load in two-step pillar mining. In this study, the adjacent structure of pillar and filling body in an underground mine was simplified as the rock-filling combination specimen $[33,34]$. Under the effect of cycle blasting dynamic disturbance during stoping, the dynamic mechanical properties of the pillar can be considered as cyclic dynamic impact $[35,36]$, which provides a basis for damage control of pillar stoping blasting construction in two steps.

\section{One-Dimensional Dynamic and Static Combination Loading Test}

2.1. Preparation of Rock Samples. Dolomite marble (DM) was taken as the research subject, which was taken from the middle of 285 section of Dahongshan Copper Mine, Yuxi City, Yunnan Province; its basic mechanical parameters are shown in Table 1 . The tailings cemented filling body (CTB) is made by mixing Portland cement 325\# of graded tailings with tap water from Dahongshan Copper Concentrator; the concentration of CTB slurry used in this test was $72 \%$, and the cement-sand ratio was $1: 4$ and $1: 6$, denoted as $\mathrm{CTB}_{1: 4}$ and $\mathrm{CTB}_{1: 6}$. With SCQ-4A automatic rock cutter, DM and CTB were made into composite specimen DM-CTB with the size of $50 \mathrm{~mm} \times 50 \mathrm{~mm}$ (diameter $\times$ height), as shown in Figure 1; the preparation conditions met the impact test requirements in ISRM.

\subsection{Test Equipment and Scheme}

2.2.1. Experimental Equipment. In this research, the test was carried out using the SHPB (split-Hopkinson pressure bar) pressure rod separator in the Rock Mechanics Laboratory of Kunming University of Science and Technology, as shown in Figure 2. The main components include power wheel drive, elastic compression bar, damping absorption, signal collection, data storage, and processing. The elastic pressure rod is made of $40 \mathrm{Cr}$ high-strength alloy steel, its diameter of is $50 \mathrm{~mm}$, the elastic modulus is $210 \mathrm{GPa}$, and the density is $7810 \mathrm{~kg} / \mathrm{m}^{3}$; the $\mathrm{p}$-wave velocity is $5100 \mathrm{~m} / \mathrm{s}$.

2.2.2. Experimental Principle. In the SHPB test, there are two basic assumptions, including the one-dimensional stress wave propagation and stress uniformity. The "three-wave method" [37] was used to process the collected strain wave signal. The stress $\sigma(t)$, strain $\varepsilon(t)$, and strain rate $\dot{\varepsilon}(t)$ can be expressed as

$$
\left\{\begin{array}{l}
\sigma(t)=\frac{A_{0} E_{0}}{2 A_{c}}\left[\varepsilon_{I}(t)+\varepsilon_{R}(t)+\varepsilon_{T}(t)\right] \\
\varepsilon(t)=\frac{C_{0}}{L} \int_{0}^{t}\left[\varepsilon_{I}(t)-\varepsilon_{R}(t)-\varepsilon_{T}(t)\right] \mathrm{d} t, \\
\dot{\varepsilon}(t)=\frac{C_{0}}{L}\left[\varepsilon_{I}(t)-\varepsilon_{R}(t)-\varepsilon_{T}(t)\right]
\end{array}\right.
$$

where $A_{0}$ is the cross-sectional area of the pressure rod; $E_{0}$ is the elastic modulus of the pressure rod system; $A_{\mathrm{c}}$ is the cross-sectional area of the combined specimen; $L$ is the length of the combined specimen; $C_{0}$ is the elastic wave velocity in the pressure bar; $\varepsilon_{I}(t)$ is the incident wave strain measured experimentally; $\varepsilon_{R}(t)$ is reflected wave strain; and $\varepsilon_{T}(t)$ is the transmitted wave strain.

According to the stress wave propagation theory and energy conservation law, $W_{I}, W_{R}, W_{T}$, and $W_{D}$, which, respectively, represent the incident energy, can reflect the energy and transmitted energy in the experimental process, and the absorbed energy that causes the specimen to fail can be calculated as follows:

$$
\left\{\begin{array}{c}
W_{I}=A_{0} C_{0} E_{0} \int_{0}^{t} \varepsilon_{I}^{2}(t) \mathrm{d} t \\
W_{R}=A_{0} C_{0} E_{0} \int_{0}^{t} \varepsilon_{R}^{2}(t) \mathrm{d} t \\
W_{T}=A_{0} C_{0} E_{0} \int_{0}^{t} \varepsilon_{T}^{2}(t) \mathrm{d} t \\
W_{D}=W_{I}-W_{R}-W_{T} .
\end{array}\right.
$$

The energy ratio $\dot{W}$ is calculated as in formula (4), where $W_{I}$ is the general name of reflected energy, transmitted energy and absorbed energy. 
TABLE 1: Basic static mechanical parameters of $\mathrm{DM}, \mathrm{CTB}_{1: 4}$, and $\mathrm{CTB}_{1: 6}$.

\begin{tabular}{lccccc}
\hline Specimen & Compressive strength $(\mathrm{MPa})$ & Modulus of elasticity $(\mathrm{GPa})$ & Poisson's ratio & Density $\left(\mathrm{kg} \cdot \mathrm{m}^{-3}\right)$ & ${\text { Wave velocity }\left(\mathrm{m} \cdot \mathrm{s}^{-1}\right)}$ \\
\hline $\mathrm{DM}$ & 53.32 & 78.71 & 0.20 & 2.93 & 5800 \\
$\mathrm{CTB}_{1: 4}$ & 2.93 & 0.63 & 0.30 & 1687.3 & 1898 \\
$\mathrm{CTB}_{1: 6}$ & 1.59 & 0.45 & 0.32 & 1735.2 & 1878 \\
\hline
\end{tabular}
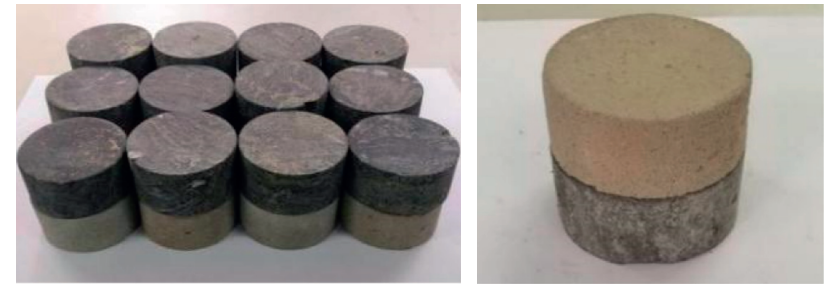

Figure 1: DM-CTB.

$$
\dot{W}=\frac{W_{X}}{W_{I}}
$$

2.2.3. Test Scheme. In this impact test, the combined specimens DM and CTB were, respectively, used as the incident end and the transmission end [38-40]. The impact pressure (replaced by $I p$ ) was selected as $0.2 \mathrm{MPa}$ and $0.24 \mathrm{MPa}$. Five cycles of impact tests were carried out on $\mathrm{DM}^{-\mathrm{CTB}_{1: 4}}$ and $\mathrm{DM}-\mathrm{CTB}_{1: 6}$ specimens to simulate the cumulative damage and failure effect of multiple blasting stoping on adjacent cemented backfill.

\section{Test Results and Analysis}

3.1. Stress-Strain Curve Relationship. Figures 3(a) and 3(b), respectively, show the stress-strain curves of the combined specimens with the total ratio of beams under different air pressures after cyclic impact, and $n$ represents the number of cyclic shocks $[41,42]$.

(1) In the first impact cycle, for DM and CTB, the compressive springback process of pores or cracks was observed, and the stress-strain curve of the combined specimen was approximately a straight line. The impact contact surface is the DM end, and the material is dense and of high strength; therefore, the initial deformation was small, and the dynamic strength increased rapidly. Besides, as the CTB material was gradually compacted, the dynamic strength continued to increase. Because the load applied on the composite specimen was not enough to cause new cracks, they mainly show linear elastic characteristics.

(2) As the number of cycles increased, the stress-strain curves of the four groups of different combinations showed an upward convex trend. Compared with the previous stage, the growth rate and the slope of the curves were both gradually decreased. When the peak dynamic strength was reached, the stress-strain curves showed an obvious "inflexion point." The phenomenon of strain rebound was obvious. When $I p=0.2 \mathrm{MPa}$ and $I p=0.24 \mathrm{MPa}$, the peak stress of

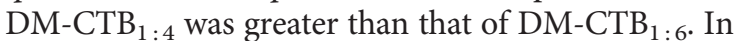
the post-peak deformation and failure stage, the slope gradually slowed down, indicating that DM-CTB gradually transformed into the plastic zone. The damage degree of the backfill part was further increased, resulting in the crack propagation inside DM-CTB and forming macrofault surface, resulting in visible macroscopic prominent cracks being formed on the surface of DM-CTB (Figure 4).According to Figures 3 and 5, it can be seen that the mechanical properties of $\mathrm{DM}$ - the filling body-mainly determine CTB, and the destruction of CTB leads to the deterioration of the overall mechanical properties of the combined specimen.

(3) For DM-CTB $1: 4$, when Ip $=0.2 \mathrm{MPa}$ and $I p=0.24 \mathrm{MPa}$, in the process of cyclic impact, the stress-strain curve began to show the characteristics of ductile materials; because CTB has certain viscoelasticity, the microdefects inside the backfill were compacted to become closer during cyclic impact. After 5 cycles of impact, the overall mechanical properties of DM-CTB were weakened, showing the characteristics of ductile materials. When $I p=0.2 \mathrm{MPa}$ and strain rate was within a certain range, $\mathrm{DM}-\mathrm{CTB}_{1: 6}$ showed strong viscoelastic characteristics during cyclic impact. When $I p=0.24 \mathrm{MPa}$, as the strain rate increased, DM$\mathrm{CTB}_{1: 6}$ showed brittle characteristics. Therefore, brittle deformation characteristics were reflected in the stress-strain curve of DM-CTB.

(4) It was analyzed that for DM-CTB, in the early stage of the cycle impact, cracks are easily spread through the filling body and the interface area, a microdefect in the CTB collapses, making the number of cracks increase with the increase of impact times; thus, internal cracks of CTB were developed, and the strength and deformation ability were decreased, making DM-CTB exhibit mechanical properties of ductile materials.

3.2. Energy Evolution Law under Cyclic Impact Load. During the SHPB impact test, the incident energy is mainly closely related to the impact velocity of the bullet. However, the reflected energy, transmitted energy, and dissipated energy are mainly determined by the characteristics of DM- 


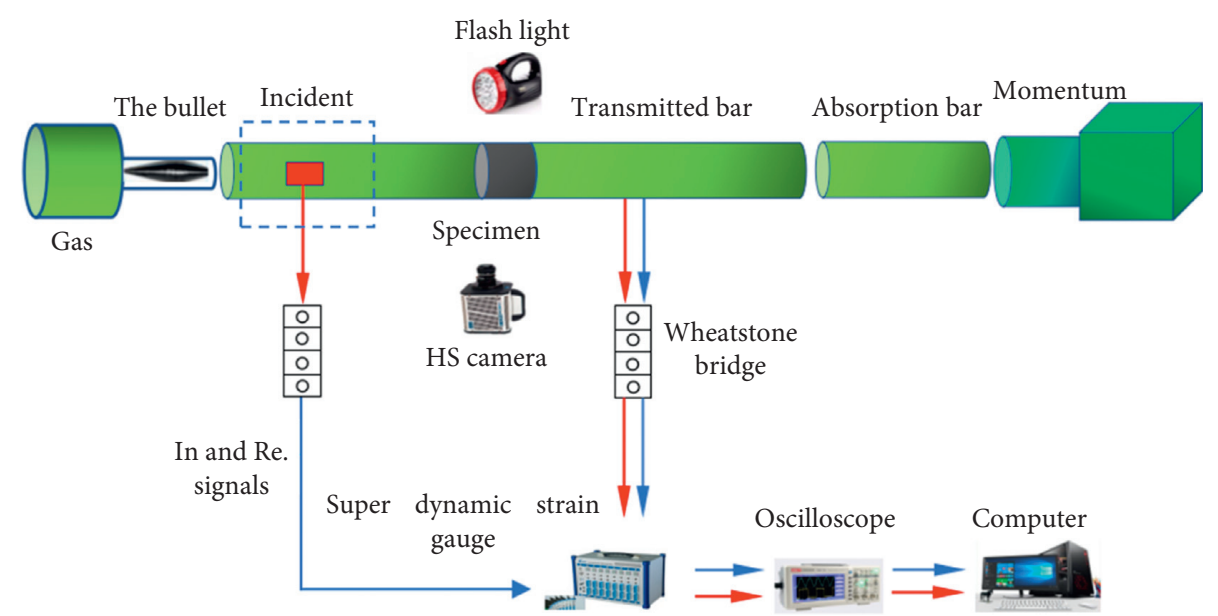

FIgURE 2: SHPB test device.
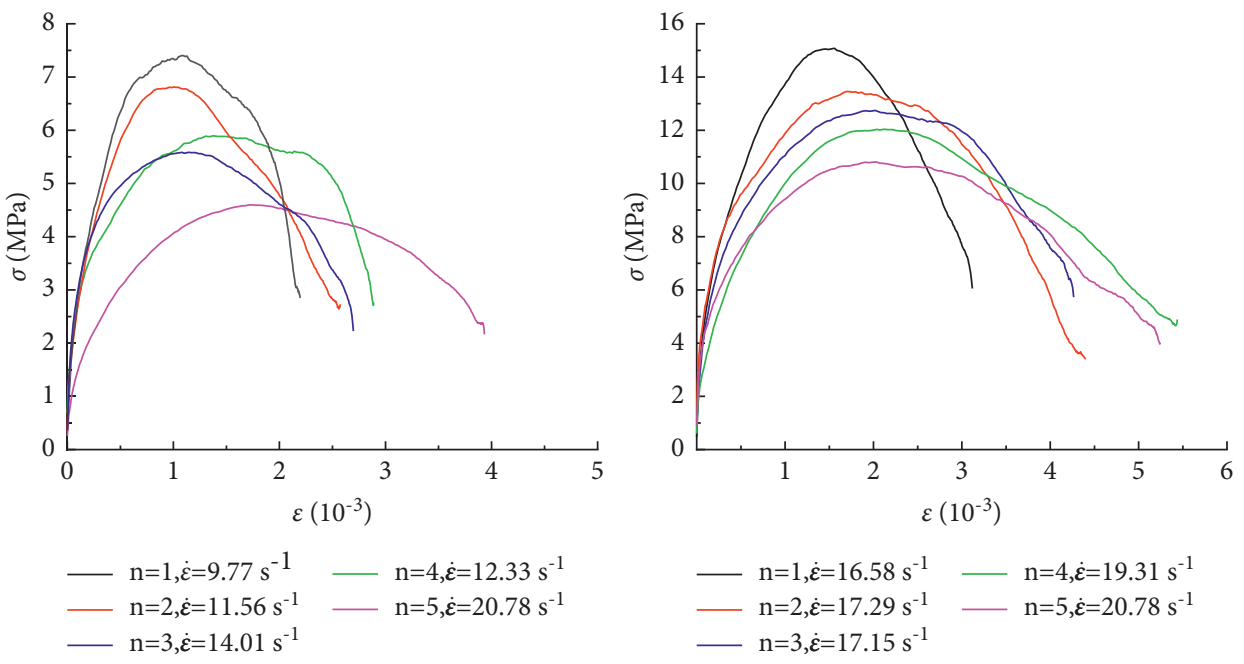

(a)
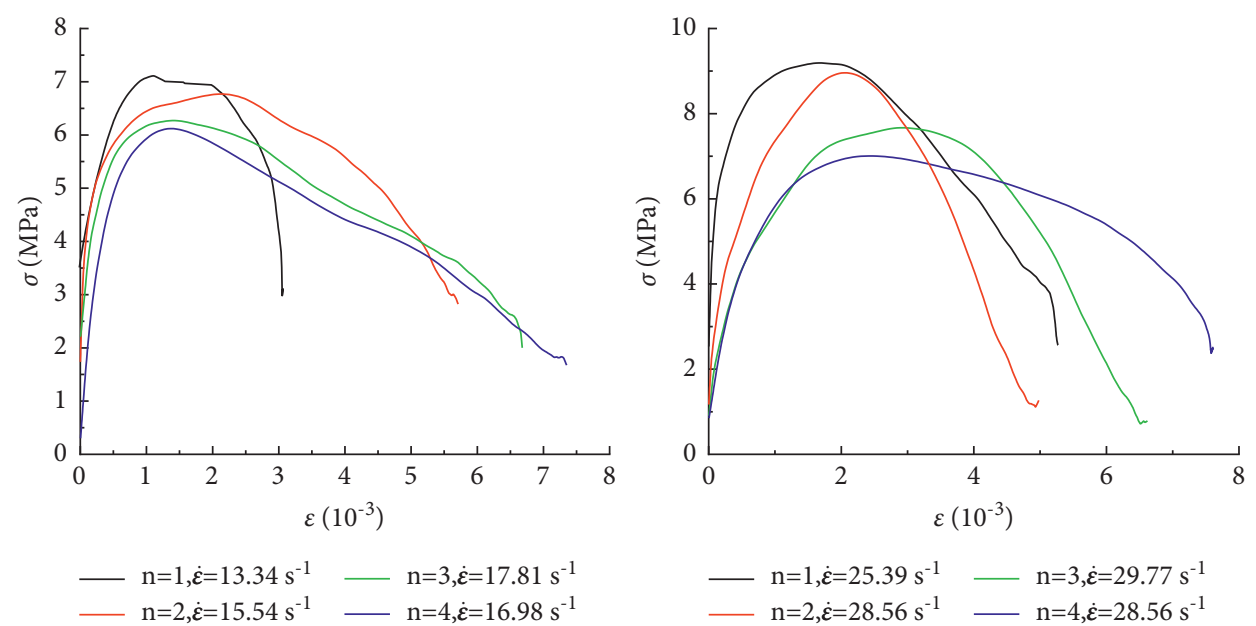

(b)

FIgure 3: Cycle impact stress-strain curve of the specimens. (a) DM-CTB 1:4. $^{\text {. (b) DM-CTB }}$ 1:6.

CTB and the difference between DM-CTB and the elastic pressure bar. The parameter of energy ratio is introduced to better describe the fluctuation response in the impact process. Under different test conditions, the corresponding $W_{X}$ can be calculated according to the stress wave related parameters, and then the energy ratio $\dot{W}$ (reflection ratio $F$, 


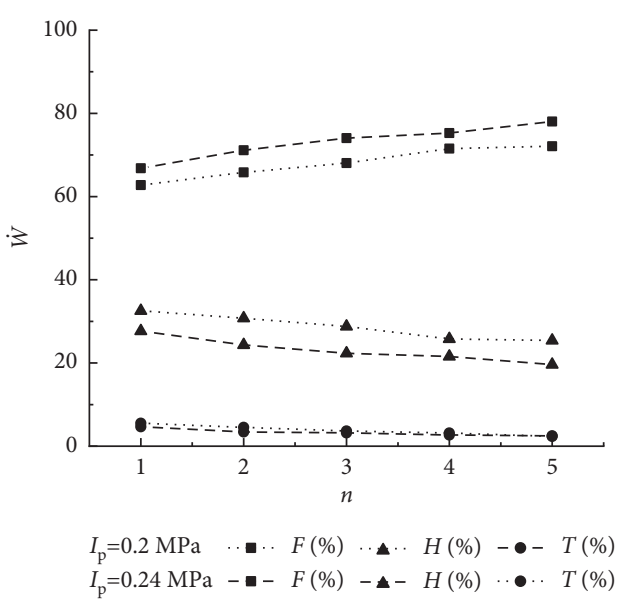

(a)

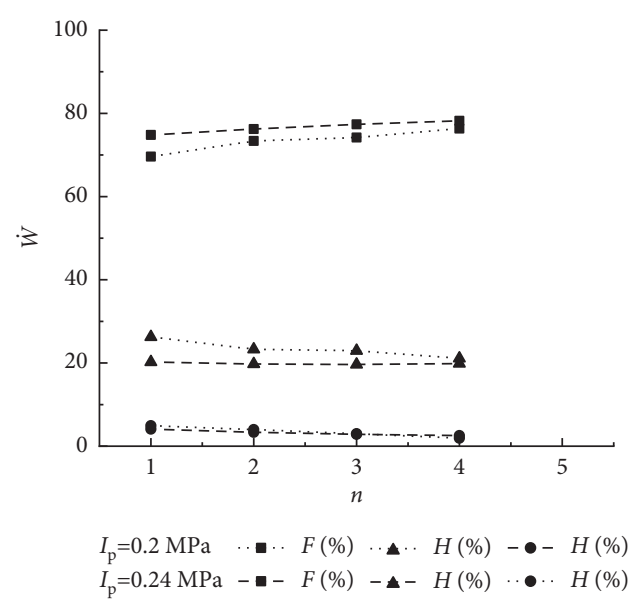

(b)

Figure 4: The energy ratio under different impact pressure curves with impact time change. (a) DM-CTB $1: 4 \cdot$ (b) DM-CTB $1: 6$.

transmission ratio $T$, and dissipation ratio $H$ ) and the energy ratio of the cyclic impact test can be calculated and recorded, as shown in Table 2, in which $W_{R}$ is reflected energy, $W_{T}$ is transmitted energy, and $W_{L}$ is the dissipated energy.

It can be seen from Figure 4 that the energy reflection ratio of DM-CTB with different air pressure was greater than $60 \%$; the reason is that the wave impedance of DM-CTB differs greatly from that of SHPB rod, and most of the energy was dissipated in the form of the reflected wave.

When the impact pressure Ip increased from $0.2 \mathrm{MPa}$ to $0.24 \mathrm{MPa}$, the reflection ratio $F$ of DM-CTB with different proportions increased; it was also found that when Ip of impingent pressure did not change, the transmission ratio $T$ and dissipation ratio $H$ of $\mathrm{DM}-\mathrm{CTB}_{1: 6}$ were lower

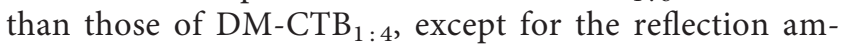
plitude $F$. To a certain extent, it is indicated that DM-CTB of low-ratio specimens has weak transmission performance and strong reflection ability; this can be explained as follows: the content of cement in the CTB part of DM$\mathrm{CTB}_{1: 6}$ is low, the internal bond is weak, and the adhesion and cohesion between particles are relatively low, so the bond between mortar and tailings aggregate is poor, inducing a large number of original microdefects in the interior. When the stress wave propagates in the combined specimen, the incident energy is readily absorbed at the defect.

In the cyclic impact stage, DM-CTB experienced a transition from fatigue damage to failure stage. In the fatigue damage stage, the initial cyclic impact has a certain strengthening effect on the specimen structure and improves the impact resistance and deformation resistance of DM-CTB; with the increase of impact number $n$, the internal damage degree of DM-CTB was aggravated to activate more internal microcracks, increasing the number of defects. As the wave impedance of specimens was decreased and the ability to resist external loads was weakened, the combined specimens showed a decreasing trend in transmission ratio $T$, dissipation ratio $H$, and reflection ratio $F$.

\section{Failure Pattern and Damage Rule of Composite Specimens under Cyclic Impact}

4.1. Failure Modes of Composite Specimens under Cyclic Impact. It can be seen from Figure 5(a) that under the condition of $I p=0.2 \mathrm{MPa}$, DM-CTB $1: 4$ did not show obvious failure when $n=1$; when $\mathrm{n}=2, \mathrm{CTB}_{1: 4}$ began to produce transverse cracks; when $\mathrm{n}=3$, it started to flake at the edges; when $n=4, C_{1: 4}$ showed shear failure; when $\mathrm{n}=5, \mathrm{CTB}_{1: 4}$ showed failure instability and partial crushing. With the increase of the number of cyclic loading, the fragmentation degree of $\mathrm{CTB}_{1: 4}$ increased and the fragmentation size decreased; however, according to the shape of fragments, the fracture surfaces are mainly parallel to the length direction of sample $\mathrm{CTB}_{1: 4}$, and most of them are transverse tensile failures. When $I p=0.2 \mathrm{MPa}, \mathrm{DM}-\mathrm{CTB}_{1: 6}$ showed tensile failure accompanied by edge breakage; the reason is that at the end of the transmission bar, cracks and fracture zones appeared in CTB under the effect of impact loading. Under the action of axial impact compression. The fracture area is prone to stress concentration, and there is reflective stretching between the interfaces. The filling body near the end of the transmission rod is more likely to be broken.

After cyclic impact loading, by comparing Figure 5(a) with Figure 5(b), it can be seen that in $\mathrm{DM}^{-\mathrm{CTB}_{1: 4}}$ combined specimen, the deformation failure of CTB is faster than that of $I p=0.24 \mathrm{MPa}$ when $I p=0.24 \mathrm{MPa}$. By comparing Figure 5(c) with Figure 5(d), it can be known that when $I p=0.24 \mathrm{MPa}$, the CTB exhibited larger deformation and more obvious failure. As shown in Figures 5(a)-5(d), under the same impact pressure, the CTB part in DM-CTB showed a higher degree of tensile and shear failure, indicating that the overall strength of DM-CTB with a small ratio is weak. The springback deformation of $\mathrm{DM}^{-\mathrm{CTB}_{1: 6}}$ aggravated the deformation failure of the lower part of the specimen and weakened the stability of the skeleton structure. According to Figure 5, when $\mathrm{DM}^{-\mathrm{CTB}_{1: 6}}$ was damaged, DM-CTB $1: 4$ was still in the elastic deformation 


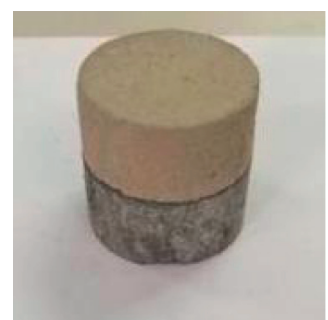

$\mathrm{n}=1, \dot{\varepsilon}=9.77 \mathrm{~s}^{-1}$

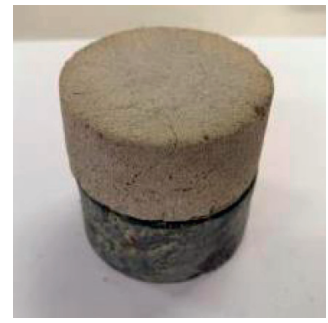

$\mathrm{n}=1, \dot{\varepsilon}=16.58 \mathrm{~s}^{-1}$

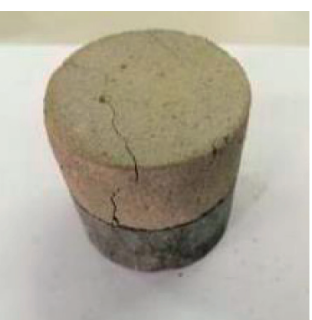

$\mathrm{n}=2, \dot{\varepsilon}=11.56 \mathrm{~s}^{-1}$

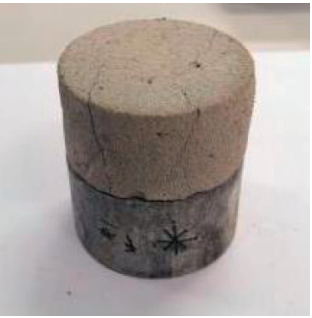

$\mathrm{n}=2, \dot{\varepsilon}=17.29 \mathrm{~s}^{-1}$

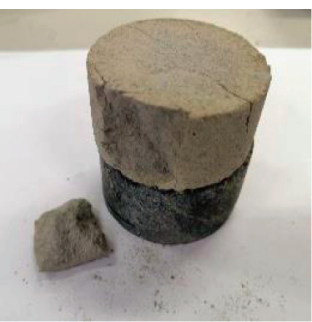

$\mathrm{n}=3, \dot{\varepsilon}=14.01 \mathrm{~s}^{-1}$

(a)

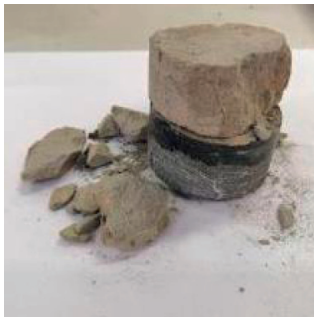

$\mathrm{n}=3, \dot{\varepsilon}=17.15 \mathrm{~s}^{-1}$

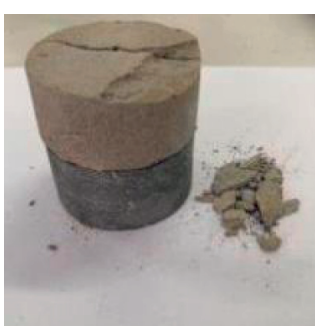

$\mathrm{n}=4, \dot{\varepsilon}=12.33 \mathrm{~s}^{-1}$

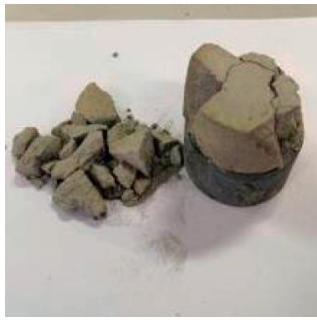

$\mathrm{n}=4, \dot{\varepsilon}=19.31 \mathrm{~s}^{-1}$

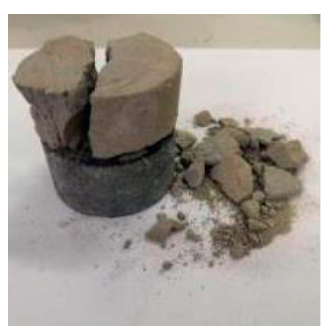

$\mathrm{n}=5, \dot{\varepsilon}=15.21 \mathrm{~s}^{-1}$

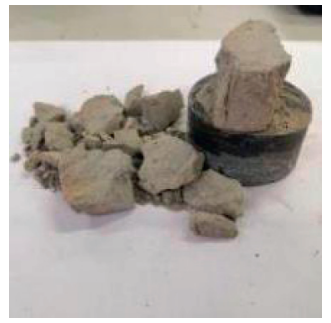

$\mathrm{n}=5, \dot{\varepsilon}=20.78 \mathrm{~s}^{-1}$

(b)

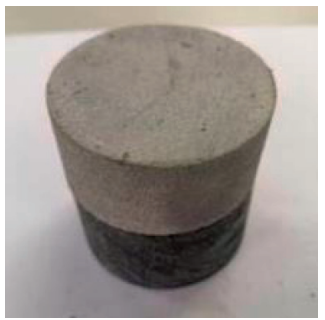

$\mathrm{n}=1, \dot{\varepsilon}=13.34 \mathrm{~s}^{-1}$

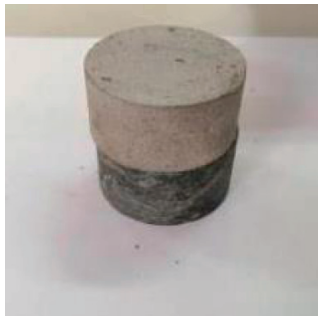

$\mathrm{n}=1, \dot{\varepsilon}=25.39 \mathrm{~s}^{-1}$

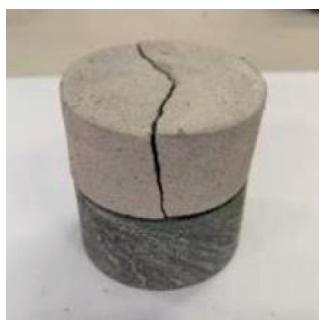

$\mathrm{n}=2, \dot{\varepsilon}=15.44 \mathrm{~s}^{-1}$

(c)

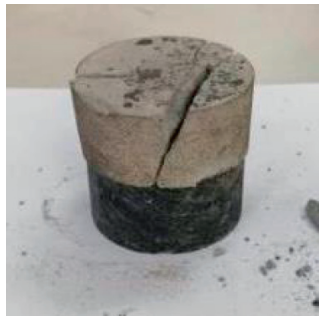

$\mathrm{n}=2, \dot{\varepsilon}=27.53 \mathrm{~s}^{-1}$

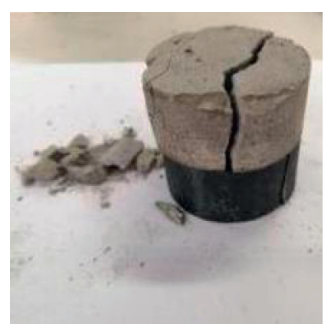

$\mathrm{n}=3, \dot{\varepsilon}=17.81 \mathrm{~s}^{-1}$

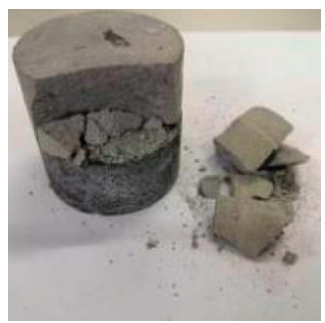

$\mathrm{n}=3, \dot{\varepsilon}=29.77 \mathrm{~s}^{-1}$

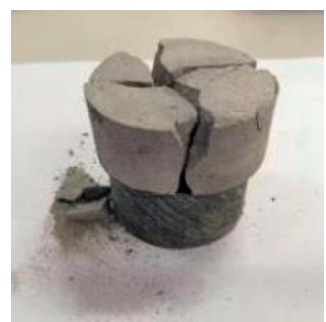

$\mathrm{n}=4, \dot{\varepsilon}=16.98 \mathrm{~s}^{-1}$

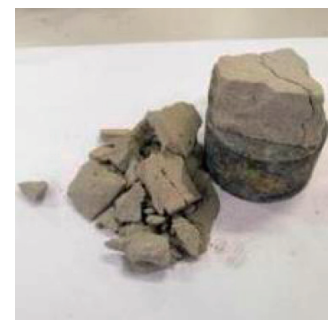

$\mathrm{n}=4, \dot{\varepsilon}=28.56 \mathrm{~s}^{-1}$

(d)

FIGURE 5: Combination of specimen failure pattern impact process

(a) $I p=0.2 \mathrm{MPa}, \mathrm{DM}-\mathrm{CTB}_{1: 4}$

(b) Ip $=0.24 \mathrm{MPa}, \mathrm{DM}-\mathrm{CTB}_{1: 4}$.

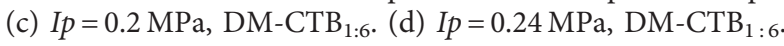

stage with no cracks or some internal microcracks produced, and the plastic deformation was incomplete. Moreover, the impact of low strain rate had a certain "reinforcing" effect on the specimen structure, and its impact resistance and deformation resistance were improved in the short term.

In conclusion, under the action of cyclic impact load, both ends of DM-CTB showed an end effect, which leads to stress concentration; at the same time, compression zones are formed at both ends of DM-CTB, resulting in cracks being parallel to the axial direction. With the increase of compressive stress, a potential shear failure surface is formed, and some cracks of the filling body in DM-CTB will further be expanded, finally forming a macroscopic failure surface. In the shear failure surface area, CTB samples will fall off due to the impact and exhibit compression shear failure. However, CTB will lose its bearing capacity and break into many small pieces when the dynamic load strength exceeds the residual strength of CTB.

For the same ratio, under the cyclic impact, the larger the impact pressure is, the more obvious the deformation failure of DM-CTB is. Under the same impact pressure, CTB in DM-CTB with a low ratio is more serious, and the mass of fragments increases accompanied by fine powder. The failure mode is mainly crushing failure, but the DM part is 
TABLE 2: Cyclic impact test results of combined specimens.

\begin{tabular}{|c|c|c|c|c|c|c|c|c|}
\hline$v / \mathrm{m} \bullet \mathrm{s}^{-1}$ & $n$ & $W_{I} / \mathrm{J}$ & $W_{R} / \mathrm{J}$ & $W_{T} / \mathrm{J}$ & $W_{L} / \mathrm{J}$ & $F / \%$ & $T / \%$ & $H / \%$ \\
\hline 2.06 & 1 & 6.85 & 4.6 & 0.32 & 1.93 & 62.77 & 4.67 & 32.55 \\
\hline 2.23 & 2 & 7.02 & 4.92 & 0.24 & 1.86 & 65.81 & 3.42 & 30.77 \\
\hline 2.15 & 3 & 6.57 & 4.67 & 0.21 & 1.69 & 68.04 & 3.20 & 28.77 \\
\hline 2.24 & 4 & 6.32 & 4.62 & 0.17 & 1.53 & 71.52 & 2.69 & 25.79 \\
\hline 2.31 & 5 & 6.81 & 5.01 & 0.17 & 1.63 & 72.10 & 2.50 & 25.40 \\
\hline 3.42 & 1 & 13.92 & 9.55 & 0.47 & 3.9 & 66.81 & 5.53 & 27.66 \\
\hline 3.53 & 2 & 12.78 & 9.15 & 0.38 & 3.25 & 71.13 & 4.54 & 24.33 \\
\hline 3.40 & 3 & 14.56 & 10.78 & 0.32 & 3.46 & 74.04 & 3.64 & 22.32 \\
\hline 3.60 & 4 & 13.31 & 10.02 & 0.23 & 3.06 & 75.28 & 3.16 & 21.56 \\
\hline 3.56 & 5 & 13.67 & 10.37 & 0.2 & 3.1 & 78.05 & 2.34 & 19.60 \\
\hline 2.07 & 1 & 6.32 & 4.64 & 0.40 & 1.28 & 69.62 & 4.11 & 26.27 \\
\hline 2.11 & 2 & 6.57 & 4.82 & 0.33 & 1.42 & 73.36 & 3.35 & 23.29 \\
\hline 2.29 & 3 & 6.97 & 5.17 & 0.25 & 1.55 & 74.18 & 2.87 & 22.96 \\
\hline 2.18 & 4 & 6.68 & 5.10 & 0.19 & 1.39 & 76.35 & 2.54 & 21.11 \\
\hline 3.87 & 1 & 13.39 & 10.02 & 0.56 & 2.81 & 74.83 & 4.93 & 20.24 \\
\hline 3.92 & 2 & 14.27 & 10.88 & 0.53 & 2.86 & 76.24 & 3.99 & 19.76 \\
\hline 3.67 & 3 & 13.95 & 10.79 & 0.42 & 2.74 & 77.35 & 3.01 & 19.64 \\
\hline 3.53 & 4 & 14.05 & 10.99 & 0.27 & 2.79 & 78.22 & 1.92 & 19.86 \\
\hline
\end{tabular}

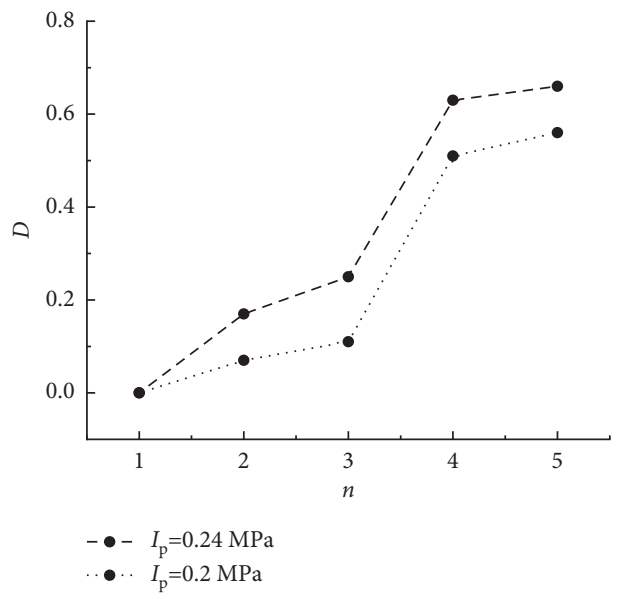

(a)

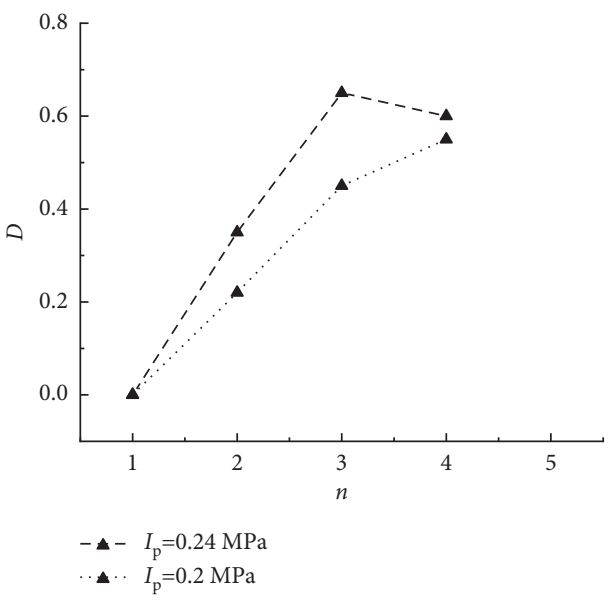

(b)

FiguRE 6: The variation curve of damage variable D with impact number under two impact pressures. (a) DM-CTB $1: 4$. (b) DM-CTB $1: 6$.

nearly not broken accompanied by transverse deformation on the end face of the DM part of the transmission end. Only a few parts of DM show tensile cracks. With the increase of Ip of impact pressure, the development of tensile cracks in the DM part deepens, but in general, the crack development is not obvious.

4.2. Damage Rule of Composite Specimens under Cyclic Impact. When $I p=0.2 \mathrm{MPa}$ and $I p=0.24 \mathrm{MPa}$, each impact on DM-CTB will cause new damage on the original basis, which means the damage will be accumulated. Referring to the loading and unloading process, damage variable $D$ is defined as follows:

$$
D=1-\frac{E_{n}}{E}
$$

where $E$ is the initial elastic modulus and $E_{n}$ is the elastic modulus after cycles of loading and unloading.
However, $D$ is difficult to characterize the initial damage degree. In order to better reflect the damage change, the dynamic elastic modulus after the initial impact is taken as the benchmark, and the damage variable $D$ after the initial impact is set as "0"; thus, the relationship between ratio, impact pressure duration, and cumulative damage variables can be established and shown in Figure 6.

It can be seen from Figure 6 that when $I p=0.2 \mathrm{MPa}$, $\mathrm{DM}^{-C T B} \mathrm{C}_{1: 4}$ had little influence on the finish before the damage threshold was reached. As the number of hits increases, damage variable $\mathrm{D}$ accumulates nonlinearly, but the rate was generally lower than the cyclic impact of higher impulse.

Taking DM-CTB ${ }_{1: 4}$ as an example, when $I p=0.2 \mathrm{MPa}$, after 5 cycles of the impact, the damage variable $D$ (counting from the second time) was $0.07,0.11,0.51$, and 0.56 , respectively. When $I p=0.24 \mathrm{MPa}$, the damage variable $D$ was $0.17,0.29,0.55$, and 0.66 ; DM-CTB $1: 6$ also showed a similar 
change. The results show that after being subjected to cyclic impact load, internal damage of DM-CTB accumulated continuously, and the internal structure was relatively stable and not easy to deform at the initial impact. With the increase of impact duration, its internal cracks and the damage variable $D$ increased rapidly. The results show that although there was damage inside the retained pillar, it still had a certain bearing capacity. With the increase of cycle number and impact pressure, the cumulative damage variable increased gradually and tended to be flat when the rock sample was destroyed, indicating that with the progress of cyclic impact, the rock sample continuously absorbed energy for the expansion and development of cracks.

As shown in Figures 5 and 6, under the condition of the same ratio and the same number of impacts, the growth rate of the damage variable $D$ of the composite specimen was relatively low when the impact pressure was small. In the pillar recovery construction site, both the cemented pillar and the reserved pillar were affected by the impact. According to the test results, the explosive amount should be appropriately reduced, and increasing the number of blasting can reduce the damage of cemented pillars and reserved pillar caused by blasting disturbance to improve the stability of stope.

\section{Conclusion}

For $\mathrm{DM}-\mathrm{CTB}_{1: 4}$ and $\mathrm{DM}-\mathrm{CTB}_{1: 6}$, under the pressure of $0.2 \mathrm{MPa}$ and $0.24 \mathrm{MPa}$, cyclic impact tests were carried out to study the energy dissipation and damage law, and conclusions can be drawn as follows:

(1) Under cyclic impact, the composite specimens experienced a transition from fatigue damage to failure stage. The structure of DM-CTB in the fatigue damage stage is "strengthened," and the impact resistance and deformation resistance are increased. After 5 cycles of shock, DM-CTB showed a decreasing trend of transmission ratio $T$ and dissipation ratio $H$ while increasing trend of reflection ratio $F$.

(2) Under the same impact pressure, as the strain rate increases and the dynamic load strength exceeds the residual strength of CTB, CTB will lose its bearing capacity and break into small pieces. In DM-CTB, the fragmentation degree of CTB increases, and the fracture is parallel to the length direction of the backfill sample, which is mostly transverse tensile failure. Tensile and shear damage degree of DM$\mathrm{CTB}_{1: 6}$ is higher than that of DM-CTB $1: 4$.

(3) For DM-TCB $1: 4$ under the cyclic impact of $I p=0.2 \mathrm{MPa}$, there is little influence on finishing when the damage threshold is not reached, and when the damage threshold exceeds 0.63 , with the increase of impact times, the increase of impact times will make the damage variables appear nonlinear accumulation, but the cumulative rate is generally less than that of the damage variables with higher impulse cyclic impact.

\section{Data Availability}

The data used to support the findings of this study are included within the article.

\section{Disclosure}

XL and QZ are co-first authors.

\section{Conflicts of Interest}

The authors declare that they have no conflicts of interest.

\section{Authors' Contributions}

XL and QZ were responsible for conceptualization, methodology, validation, data curation, visualization, and original draft preparation. QZ was responsible for experimental guidance and data analysis. JW and WS were responsible for theoretical analysis. All authors were responsible for formal analysis and review and editing. All authors have read and agreed to the published version of the manuscript.

\section{Acknowledgments}

This study was financially supported by the National Natural Science Foundation of China (nos. 51964023 and 51934003). The authors are grateful for the support.

\section{References}

[1] J. Wang, D. P. Qiao, R. S. Han, G. T. Li, and J.-C. Xie, "Strength model of cemented backfill in subsequent filling at the stage of open stope and its application," Rock and Soil Mechanics, vol. 40, no. 3, pp. 1105-1112, 2019.

[2] F. S. Ma, F. L. Jie, G. R. Lu, H. G. Guo, and Y. Y. Kou, "Backfill stability analysis of steep dip mine using filling method," Journal of Engineering Geology, vol. 26, no. 5, pp. 1351-1359, 2018.

[3] J. Wang, W. D. Song, Y. Y. Tan, J. X. Fu, and S. Cao, "Damage constitutive model and strength criterion of horizontal stratified cemented backfill," Rock and Soil Mechanics, vol. 40, no. 5, pp. 1731-1739, 2019.

[4] W. Liu, P. Zeng, L. Yan, Y. Yang, and L. S. Liu, "Mechanical properties and permeability evolution of weakly weathered rocks under cyclic impact," Journal of China Coal Society, vol. 46, no. 6, pp. 1855-1863, 2021.

[5] J. G. Wang, T. Zuo, X. L. Li, Z. H. Tao, and J. Ma, "Study on the fractal characteristics of the pomegranate biotite schist under impact loading," Geofluids, vol. 2021, Article ID 1570160, 8 pages, 2021.

[6] D. Osthus, H. C. Godinez, E. Rougier, and G. Srinivasan, "Calibrating the stress-time curve of a combined finite-discrete element method to a Split Hopkinson Pressure Bar experiment," International Journal of Rock Mechanics and Mining Sciences, vol. 106, pp. 278-288, 2018.

[7] W. R. Hu, K. Liu, D. O. Potyondy, and Q. B. Zhang, "3D continuum-discrete coupled modelling of triaxial Hopkinson bar tests on rock under multiaxial static-dynamic loads," International Journal of Rock Mechanics and Mining Sciences, vol. 134, Article ID 104448, 2020.

[8] P. Feng, Y. Xu, and F. Dai, "Effects of dynamic strain rate on the energy dissipation and fragment characteristics of cross- 
fissured rocks," International Journal of Rock Mechanics and Mining Sciences, vol. 138, Article ID 104600, 2021.

[9] Z. K. Crosby, P. M. Gullett, S. A. Akers, and S. S. Graham, "Characterization of the mechanical behavior of salem limestone containing thermally-induced microcracks," International Journal of Rock Mechanics and Mining Sciences, vol. 101, pp. 54-62, 2018.

[10] K. Liu, J. Zhao, G. Wu, A. Maksimenko, A. Haque, and Q. B. Zhang, "Dynamic strength and failure modes of sandstone under biaxial compression," International Journal of Rock Mechanics and Mining Sciences, vol. 128, Article ID 104260, 2020.

[11] Z. Y. Han, D. Y. Li, T. Zhou, Q. Q. Zhu, and P. G. Ranjith, "Experimental study of stress wave propagation and energy characteristics across rock specimens containing cemented mortar joint with various thicknesses," International Journal of Rock Mechanics and Mining Sciences, vol. 131, Article ID 104352, 2020.

[12] P. D. Xu, L. Q. Tang, Y. G. Zhang et al., "SHPB experimental method for ultra-soft materials in solution environment," International Journal of Impact Engineering, vol. 159, Article ID 104051, 2022.

[13] C. Li, D. Guo, Y. Zhang, and C. An, “Compound-mode crack propagation law of PMMA semicircular-arch roadway specimens under impact loading," International Journal of Coal Science \& Technology, vol. 8, no. 6, pp. 1302-1315, 2021.

[14] H. P. Xie, Y. Yan, and L. Y. Li, "Criteria for strength and structural failure of rocks based on energy dissipation and energy release principles," Chinese Journal of Rock Mechanics and Engineering, vol. 17, no. 24, pp. 3003-3010, 2005.

[15] P. R. Zhu, W. D. Song, L. H. Xu, J. Wang, and F. Wang, “A study on mechanical properties of cemented backfills under impact compressive loading," Journal of Vibration and Shock, vol. 37, no. 12, pp. 131-137, 2018.

[16] Y. Q. Hou, S. H. Yin, S. X. Yang, M. Z. Zhang, and H. B. Liu, "Study on the mechanical response and energy damage evolution of cemented backfill under dynamic load," Rock and Soil Mechanics, vol. 1, no. 12, pp. 8-2, 2021.

[17] J. J. Zhu, X. B. Li, F. Q. Gong, S. M. Wang, and W. He, "Experimental test and damage characteristics of sandstone under uniaxial impact compressive loads," Journal of Central South University, vol. 43, no. 7, pp. 2701-2707, 2012.

[18] D. Q. Gan, X. X. Tian, Z. Y. Liu, and F. Gao, "Study on mechanics and damage characteristics of sandstone under cyclic impact state," China Mining Magazine, vol. 30, no. 3, pp. 203-211, 2021.

[19] L. Wen, X. L. Liang, W. J. Feng et al., “An investigation of the mechanical properties of sandstone under coupled static and dynamic loading," Rock and Soil Mechanics, vol. 41, no. 11, pp. 3540-3552, 2020.

[20] Z. L. Wang, H. Yang, and N. C. Tian, "Mechanical property and damage evolution mechanism of granite under uniaxial cyclic impact," Journal of Harbin Institute of Technology, vol. 52, no. 2, pp. 59-66, 2020.

[21] Y. Liu and F. Dai, "A review of experimental and theoretical research on the deformation and failure behavior of rocks subjected to cyclic loading," Journal of Rock Mechanics and Geotechnical Engineering, vol. 13, no. 5, pp. 1203-1230, 2021.

[22] E. Liu, R. Huang, and S. He, "Effects of frequency on the dynamic properties of intact rock samples subjected to cyclic loading under confining pressure conditions," Rock Mechanics and Rock Engineering, vol. 45, no. 1, pp. 89-102, 2012.

[23] N. Erarslan and D. J. Williams, "Investigating the effect of cyclic loading on the indirect tensile strength of rocks rock mechanics and rock engineering," Rock Mechanics and Rock Engineering, vol. 45, no. 3, pp. 327-340, 2012.

[24] X. L. Yang, X. Y. Yun, Z. Wu, and C. D. Su, "The experimental study on mechanical properties of blast damaged rock," Chinese Journal of Rock Mechanics and Engineering, vol. 20, no. 4, pp. 436-439, 2001.

[25] J. F. Jin, X. B. Li, C. Qiu, W. Tao, and X. J. Zhou, "Evolution model for damage accumulation of rock under cyclic impact loadings and effect of static loads on damage evolution," Chinese Journal of Rock Mechanics and Engineering, vol. 33, no. 8, pp. 1662-1671, 2014.

[26] J. Q. Xiao, D. X. Ding, G. Xu, and F. L. Jiang, "Inverted S-shaped model for nonlinear fatigue damage of rock," International Journal of Rock Mechanics and Mining Sciences, vol. 46, no. 3, pp. 643-648, 2009.

[27] K. Zhao, M. Huang, Y. J. Yan et al., "Mechanical Properties and Cooperative deformation of cemented backfill materials with different cement-sand ratios," Chinese Journal of Rock Mechanics and Engineering, vol. 40, no. S1, pp. 2781-2789, 2021.

[28] S. Cao, W. D. Song, G. L. Xue, R. W. Ma, and P. R. Zhu, "Mechanical characteristics variation of stratified cemented tailing backfilling and its failure modes," Journal of China University of Mining \& Technology, vol. 45, no. 4, pp. 717-722+728, 2016.

[29] X. Liu, S. Song, Y. Tan, D. Fan, J. Ning, and X. Li, Y. Yin, Similar simulation study on the deformation and failure of surrounding rock of a large section chamber group under dynamic loading," International Journal of Mining Science and Technology, vol. 31, no. 3, pp. 495-505, 2021.

[30] R. S. Yang, W. Y. Li, S. Z. Fang, Y. Zhu, and Y. L. Li, "Experimental study on impact dynamic characteristics of layered composite rocks," Chinese Journal of Rock Mechanics and Engineering, vol. 38, no. 9, pp. 1747-1751, 2019.

[31] M. X. Wang, "Mechanics characteristics of cemented filling and surrounding rock," Journal of China Coal Society, vol. 44, no. 2, pp. 445-453, 2019.

[32] Y. Wang, C. K. Liu, and X. F. Yi, "Study on the Fracture evolution of cemented backfill with cemented tailings," Rock and Soil Mechanics, vol. 41, no. 10, pp. 3365-3373, 2020.

[33] X. L. Li, Z. B. Yuan, J. G. Wang, Z. G. Leng, and Y. M. Duan, "Energy transfer law and failure characteristics of rock-filling under dynamic load," Engineering Blasting, vol. 27, no. 3, pp. $1-8+34,2021$.

[34] Y. Y. Mu, X. L. Li, J. G. Wang, and Z. G. Leng, "Research on the mechanical properties and energy consumption transfer law of cement tailings backfill under impact load," Science of Advanced Materials, vol. 13, no. 5, pp. 889-898, 2021.

[35] J. G. Wang, Q. C. Gao, H. Lu, S. F. Liang, B. Huang, and Z. Yang, "SHPB experimental study on impact response of layered media," Journal of Vibration and Shock, vol. 34, no. 19, pp. 192-197+212, 2015.

[36] L. Liu, R. Li, H. Qin, and W. Sun, "Experimental SHPB study of limestone damage under confining pressures after exposure to elevated temperatures," Metals, vol. 11, no. 10, 2021.

[37] Z. Y. Zhang, J. G. Wang, Y. H. Huang, X. L. Li, and W. Zhao, "Experimental analysis on dynamic characteristics and failure mode of deep dolomite based on high-speed photography," Chinese Journal of Underground Space and Engineering, vol. 14, no. 5, pp. 195-201, 2018.

[38] X. L. Li, Z. H. Tao, J. G. Wang, T. Zuo, J. Ma, and Q. Li, "Strain rate effect on mechanical properties of cemented backfill under dynamic and static combined loading," Shock and Vibration, vol. 2021, Article ID 2196838, 11 pages, 2021. 
[39] T. Zuo, Z. H. Zhao, J. G. Wang, X. L. Li, Z. H. Tao, and C. H. Yang, "Analysis of dynamic damage fractal and energy consumption characteristics of dolomite marble," Shock and Vibration, vol. 2022, Article ID 9440222, 11 pages, 2022.

[40] Z. Y. Zhang, Q. Y. Qian, H. Wang, Y. H. Huang, J. G. Wang, and H. S. Liu, "Study on the dynamic mechanical properties of metamorphic limestone under impact loading," Lithosphere, vol. 2021, Article ID 8403502, 2021.

[41] B. Gong, S. Wang, S. W. Sloan, D. Sheng, and C. A. Tang, "Modelling rock failure with a novel continuous to discontinuous method," Rock Mechanics and Rock Engineering, vol. 52, no. 6, 2019.

[42] B. Gong, C. Tang, S. Wang, H. Bai, and Y. Li, "Simulation of the nonlinear mechanical behaviors of jointed rock masses based on the improved discontinuous deformation and displacement method," International Journal of Rock Mechanics and Mining, vol. 122, Article ID 104076, 2019. 